\title{
Gastrointestinal Stromal Tumor pT2 TNM
} Finding v7

National Cancer Institute

\section{Source}

National Cancer Institute. Gastrointestinal Stromal Tumor PT2 TNM Finding v7. NCI

Thesaurus. Code C90049.

Gastrointestinal stromal tumor with tumor size more than $2 \mathrm{~cm}$, but not more than $5 \mathrm{~cm}$, in greatest dimension. (from AJCC 7th Ed.) 